\title{
Linear Synchronous Motor Repeatability Tests
}

by

C. R. Ward

Westinghouse Savannah River Company

Savannah River Site

Aiken, South Carolina 29808

This paper was prepared in connection with work done under the above contract number with the U.S.

Department of Energy. By acceptance of this paper, the publisher and/or recipient acknowledges the U. S.

Government's right to retain a nonexclusive, royalty-free license in and to any copyright covering this paper, along with the right to reproduce and to authorize others to reproduce all or part of the copyrighted paper. 


\section{DISCLAIMER}

This report was prepared as an account of work sponsored by an agency of the United States Government. Neither the United States Government nor any agency thereof, nor any of their employees, makes any warranty, express or implied, or assumes any legal liability or responsibility for the accuracy, completeness, or usefulness of any information, apparatus, product or process disclosed, or represents that its use would not infringe privately owned rights. Reference herein to any specific commercial product, process or service by trade name, trademark, manufacturer, or otherwise does not necessarily constitute or imply its endorsement, recommendation, or favoring by the United States Government or any agency thereof. The views and opinions of authors expressed herein do not necessarily state or reflect those of the United States Government or any agency thereof.

This report has been reproduced directly from the best available copy.

Available for sale to the public, in paper, from: U.S. Department of Commerce, National Technical Information Service, 5285 Port Royal Road, Springfield, VA 22161

phone: (800) 553-6847

fax: (703) 605-6900

email: orders@ntis.fedworld.gov

online ordering: http://www.ntis.gov/help/index.asp

Available electronically at http://www.osti.gov/bridge

Available for a processing fee to U.S. Department of Energy and its contractors, in paper, from: U.S. Department of Energy, Office of Scientific and Technical Information, P.O. Box 62, Oak Ridge, TN 37831-0062

phone: (865)576-8401

fax: (865)576-5728

email: reportseadonis.osti.gov 


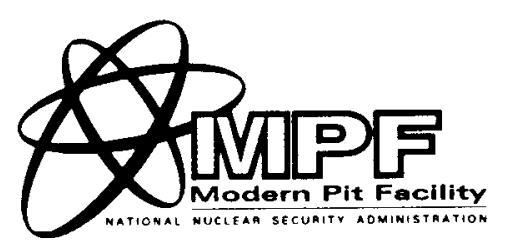

\title{
Linear Synchronous Motor Repeatability Tests (U)
}

\author{
Clyde R. Ward
}

Publication Date: September, 2002

Authorized Derivative Classifier/ Reviewing Official

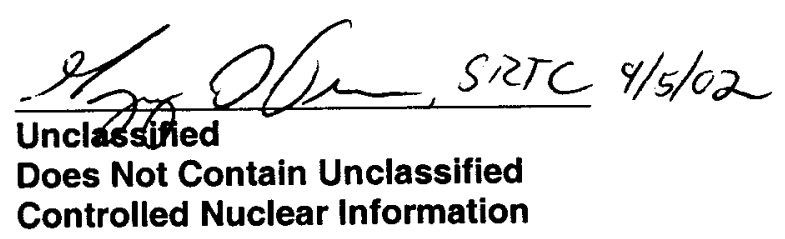

Westinghouse Savannah River Company Savannah River Site Aiken, SC 29808

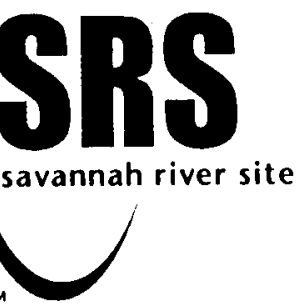

This document was prepared in connection with work done under Contract No. DE-AC09-96SR 18500 with the U. S. Department of Energy 
WSRC-TR-2002-00401

Linear Synchronous Motor Repeatability Tests (U)

Approvals

Author:

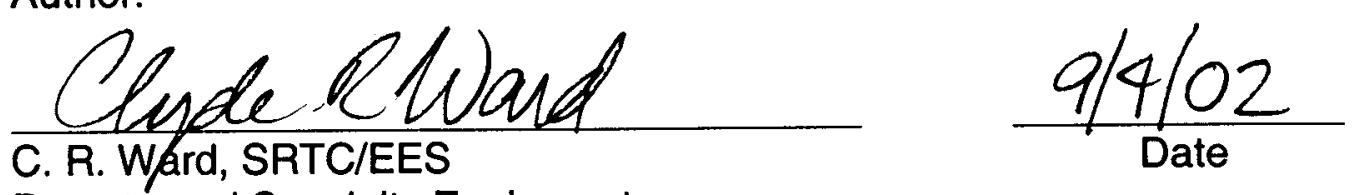

Remote and Specialty Equipment

Technical Reviewer:

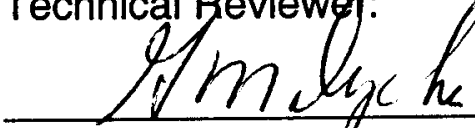

G. M. Dyches, SRTC/EES Remote and Specialty Equipment

$$
\frac{9 / 4 / 02}{\text { Date }}
$$

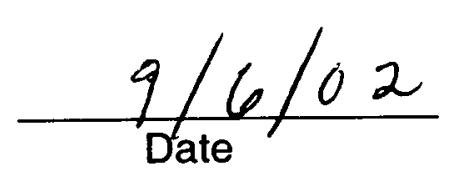

ii 


\section{TABLE OF CONTENTS}

EXECUTIVE SUMMARY




\section{LIST OF ATTACHMENTS}

Attachment 1 - Data Sheet, no weight on cart, motor test

Attachment 2 - Data Sheet, no weight on cart, gap test1

Attachment 3 - Data Sheet, $300 \mathrm{lbs}$. on cart, motor test

Attachment 4 - Data Sheet, 300 lbs. on cart, gap testA

Attachment 5 - Data Sheet, $550 \mathrm{lbs}$. on cart, motor test

Attachment 6 - Data Sheet, 550 lbs. on cart, gap test

Attachment 7 - Data Sheet, 550 lbs. on cart, motor test, profile

Attachment 8 - Data Sheet, 550 lbs. on cart, motor test, profile, decel 


\section{EXECUTIVE SUMMARY}

A cart system using linear synchronous motors is being considered for use in the material transport system to transport material between and within gloveboxes in the Modern Pit Facility (MPF). The only moving parts in this system are the cart itself and the wheels on the cart. The only components inside containment are two magnet arrays, the cart and the wheels. The linear motor primaries are located outside containment. This makes the linear synchronous motor system very desirable from a maintenance standpoint. One of the important characteristics of a transport system is its repeatability. In the case of a cart in a transport system, repeatability is the variability in positioning when the cart is moved to a specific position. A cart system using linear synchronous motors has been installed in the Savannah River Technology Center. This system was tested to determine its repeatability.

The tests determined that the repeatability for the linear synchronous motor cart system when stopping on the center of a motor with a range of gross weight from 125 to $675 \mathrm{lbs}$. was \pm 0.073 inches $( \pm 1.8 \mathrm{~mm})$. This is excellent repeatability for a cart carrying such a wide range of loads. This repeatability can be improved to \pm 0.028 inches $( \pm 0.7 \mathrm{~mm})$, if the load stops at a position completely on a motor unit and always approaches the point from a fixed distance from the same direction.

\section{INTRODUCTION}

A cart system using linear synchronous motors was being considered for the Plutonium Immobilization Plant (PIP). One of the applications in the PIP was the movement of a stack of furnace trays, filled with the waste form (pucks) from a stacking/unstacking station to several bottom loaded furnaces. A system was ordered to perform this function in the PIP Ceramic Prototype Test Facility (CPTF). This system was installed and started up in SRTC prior to being installed in the CPTF. The PIP was suspended and then canceled after the linear synchronous motor system was started up. This system was used to determine repeatability of a linear synchronous motor cart system for the Modern Pit Facility.

\section{DISCUSSION}

The PIP cart system was built to carry a relatively large payload for a glovebox system, $600 \mathrm{lbs}$. To interface with the bottom loaded furnace the cart had to be approximately $7 \frac{1}{2}$ inches off of the glovebox floor. The cart also had to be approximately 18 inches wide and $251 / 2$ inches long to accommodate the furnace trays and furnace bottom. This made the cart rather large and heavy. It weighs approximately $125 \mathrm{lbs}$. To simulate a stack of furnace trays and the furnace bottom in SRTC, eleven plates, each weighing approximately 50 lbs., were provided. For the PIP application the cart had to travel a distance of over 12 feet, so the track is 
approximately 13 feet, 4 inches long to accommodate the 25 1/2 inch long cart. The system is shown in Figure 1. A close-up of the cart is shown in Figure 2.

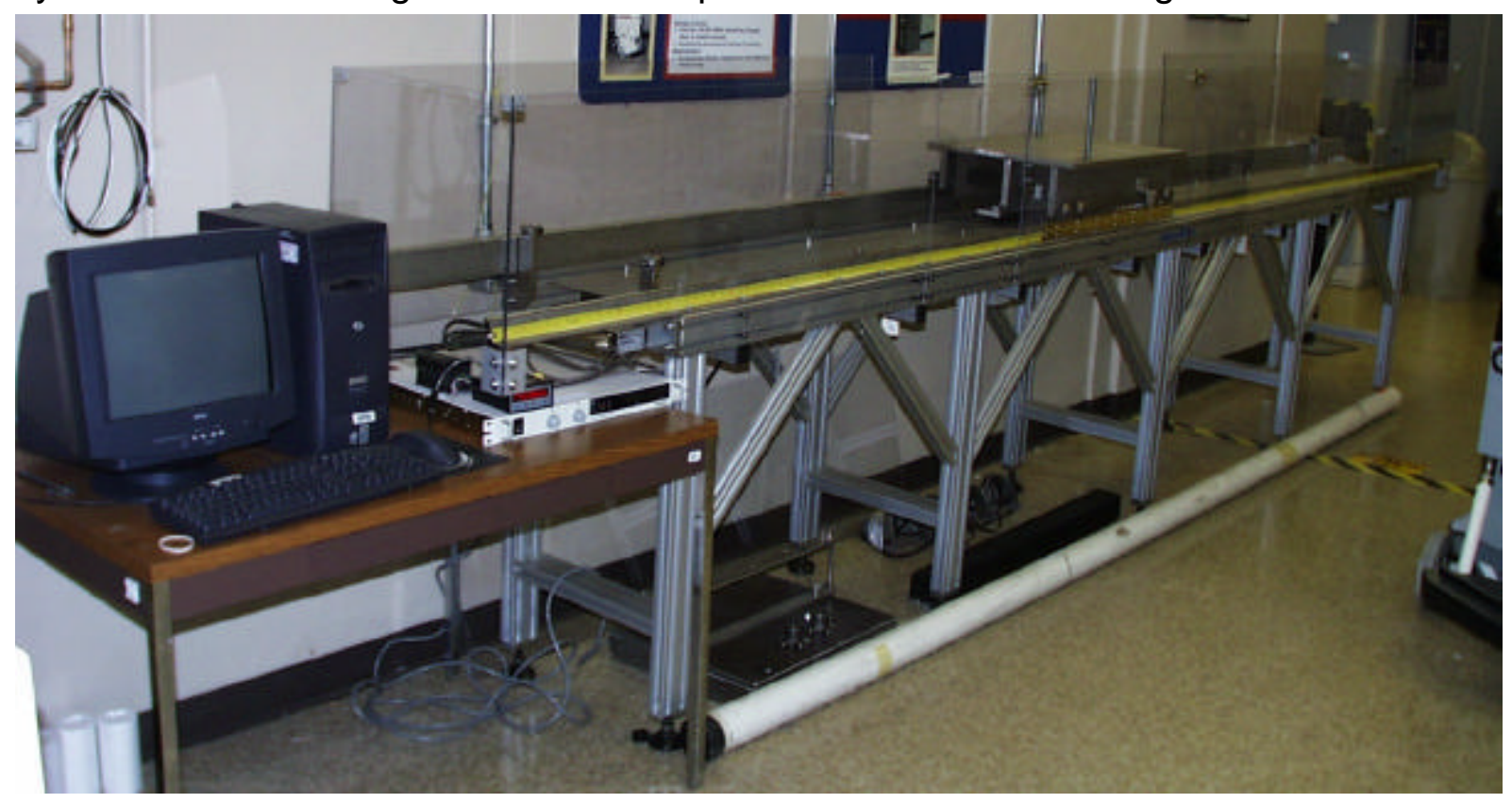

PIP Linear Synchronous Motor System

Figure 1.

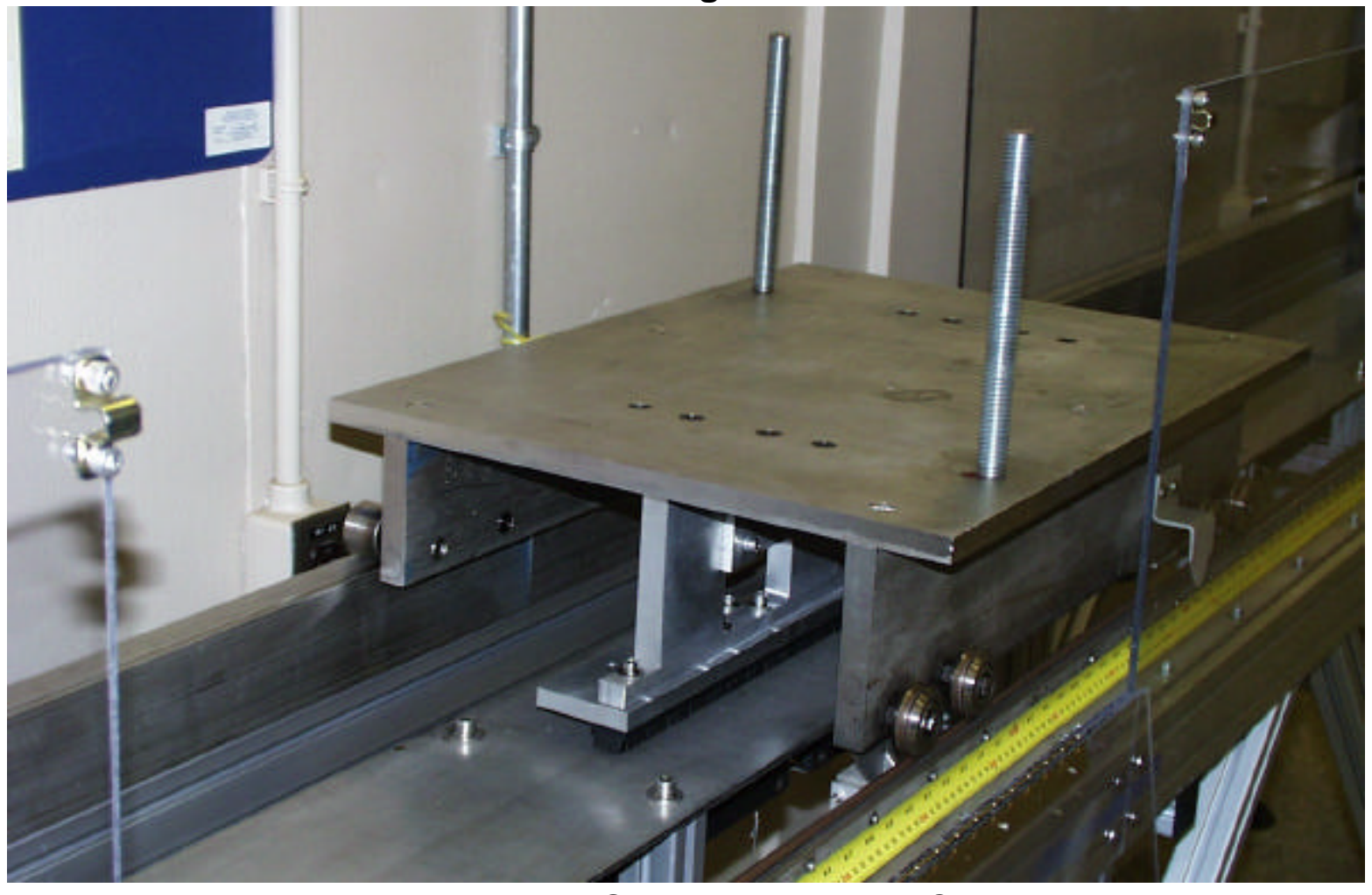

Linear Synchronous Motor Cart

Figure 2. 
Below the cart is a $3 / 16$ " thick, $304 \mathrm{~L}$ stainless steel plate to represent the glovebox floor. Two magnet arrays are attached to a plate suspended from the center of the cart. One magnet array is the motor secondary and is only about 1/16 inch above the glovebox floor. The second magnet array provides position feed back to the system and is about $3 / 8$ inch above the floor. There are four linear synchronous motor primaries in the PIP system, called QuickSticks ${ }^{\mathrm{TM}}$ by their manufacturer, MagneMotion. Each motor primary is one meter long. There is a one inch gap between each motor to simulate the ability to span a glovebox flange, air lock door or fire door. A QuickStick ${ }^{\mathrm{TM}}$ is shown in Figure 3 beside a standard flashlight for comparison. The QuickStick ${ }^{\mathrm{TM}}$ primaries are connected via a single "daisy chained" power and communications cable to a personal computer. Custom motion control software communicates with each uniquely addressable QuickStick ${ }^{\mathrm{TM}}$ primary to coordinate cart movement within and between primaries.

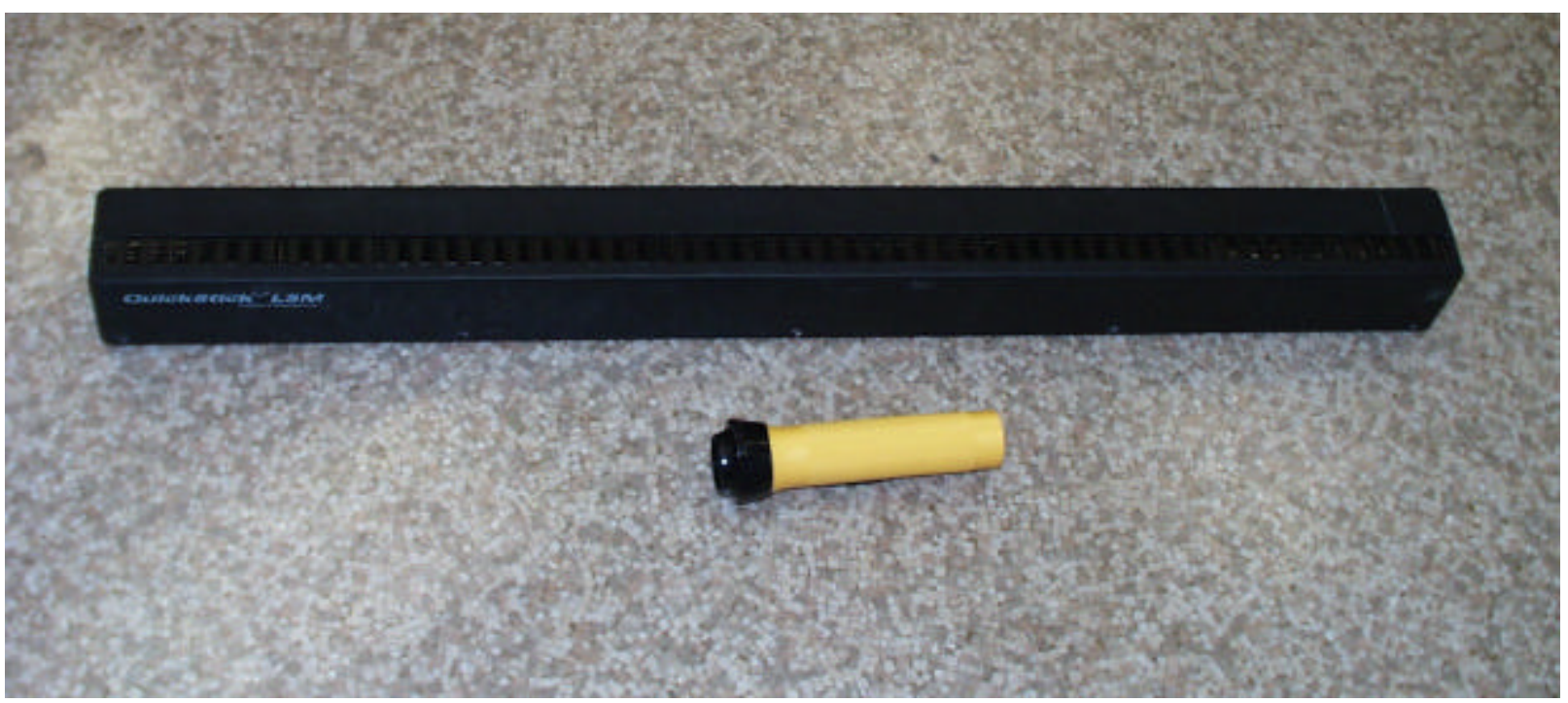

Linear Synchronous Motor Primary (with flashlight for comparison) Figure 3.

A Balluff Micropulse ${ }^{T M}$ linear transducer, model BTL-5-P1-M3606-4-S32, was installed to independently determine the position of the cart. The transducer is a magnetostrictive device. The position of a magnet moved axially along the transducer is displayed on a digital readout. The transducer has a resolution of 0.002 inch $(0.05 \mathrm{~mm})$. The repeatability of the transducer was checked by manually moving the cart against a solid end stop at each end of the track. At each end the same reading was produced in each of 10 cycles. To confirm the accuracy of the transducer, the cart was moved 3 meters (as measured by a metal tape measure installed below the cart) and the transducer displayed an increase of 3 meters.

In each of the first six repeatability tests the cart was sent to a specific position from a long distance from the left, a short distance to the left, a long distance from the right and a short distance from the right. This represents the range of locations from which 
the cart could be sent to a specific position. In each test the cart was sent from these four locations, in order, to a specific position 30 times. Since the repeatability could be different with different payloads on the cart, the tests were conducted with no weight on the cart (a gross weight of $125 \mathrm{lbs}$.), $300 \mathrm{lbs}$. on the cart (a gross weight of $425 \mathrm{lbs}$.) and $550 \mathrm{lbs}$. on the cart (a gross weight of $675 \mathrm{lbs}$.). Since the repeatability could be different depending on whether the specific position was in the center of a motor, or in the gap between motors, tests were completed for each weight with the specific position on the center of the motor and between motors.

\section{TEST RESULTS}

Eight repeatability tests were conducted. The details of each test are presented in Attachments 1-8. The results from the first six tests are summarized in Table 1.

Ranges of all moves to center of motor

\begin{tabular}{|l|r|r|r|r|r|}
\hline & \multicolumn{1}{|c|}{ weight } & \multicolumn{1}{c|}{300 lbs. } & \multicolumn{1}{c|}{550 lbs. } & $0,300,550$ & 0,300 \\
\hline high $(\mathrm{mm})$ & 1151.18 & 1150.90 & 1152.45 & 1152.45 & 1151.18 \\
\hline low $(\mathrm{mm})$ & 1150.38 & 1149.59 & 1148.74 & 1148.74 & 1149.59 \\
\hline difference $(\mathrm{mm})$ & 0.80 & 1.31 & 3.71 & 3.71 & 1.59 \\
\hline difference (in.) & 0.031 & 0.052 & 0.146 & 0.146 & 0.063 \\
\hline
\end{tabular}

Ranges of short from right moves to center of motor

\begin{tabular}{|l|r|r|r|r|r|}
\hline & \multicolumn{1}{|c|}{ weight } & \multicolumn{1}{l}{300 lbs. } & \multicolumn{1}{c|}{550 lbs. } & $0,300,550$ & 0,300 \\
\hline high $(\mathrm{mm})$ & 1150.62 & 1150.24 & 1149.68 & 1150.62 & 1150.62 \\
\hline low $(\mathrm{mm})$ & 1150.48 & 1149.96 & 1149.21 & 1149.21 & 1149.96 \\
\hline difference $(\mathrm{mm})$ & 0.14 & 0.28 & 0.47 & 1.41 & 0.66 \\
\hline difference (in.) & 0.006 & 0.011 & 0.019 & 0.056 & 0.026 \\
\hline
\end{tabular}

Ranges of all moves to gap between motors

\begin{tabular}{|l|r|r|r|r|r|}
\hline & 0 weight & \multicolumn{1}{|c|}{300 lbs. } & 550 lbs. & $0,300,550$ & 0,300 \\
\hline high $(\mathrm{mm})$ & 656.93 & 657.01 & 657.91 & 657.91 & 657.01 \\
\hline low $(\mathrm{mm})$ & 655.41 & 654.57 & 654.90 & 654.57 & 654.57 \\
\hline difference $(\mathrm{mm})$ & 1.52 & 2.44 & 3.01 & 3.34 & 2.44 \\
\hline difference (in.) & 0.060 & 0.096 & 0.119 & 0.131 & 0.096 \\
\hline
\end{tabular}

Ranges of short from right moves to gap between motors

\begin{tabular}{|l|r|r|r|r|r|}
\hline & 0 weight & \multicolumn{1}{|c|}{300 lbs. } & 550 lbs. & $0,300,550$ & 0,300 \\
\hline high (mm) & 655.98 & 656.97 & 657.62 & 657.62 & 656.97 \\
\hline low $(\mathrm{mm})$ & 655.84 & 656.35 & 657.20 & 655.84 & 655.84 \\
\hline difference (mm) & 0.14 & 0.62 & 0.42 & 1.78 & 1.13 \\
\hline difference (in.) & 0.006 & 0.024 & 0.017 & 0.070 & 0.044 \\
\hline
\end{tabular}

\section{Table 1.}

As shown in the table, the difference in the high and low readings (the range) is very low for no weight on the cart. The repeatability is one half of the range. The range for all moves to a position in the middle of a motor with no weight on the cart is 0.031 inches or a repeatability of \pm 0.016 inches. If the cart with no weight approaches a 
position in the middle of a motor from a short distance to the right, the range improves to 0.006 inches or a repeatability of \pm 0.003 inches (about $1 / 5$ ). The range (and repeatability) increases as weight on the cart increases. For example, the range of all moves to a position in the middle of a motor with $550 \mathrm{lbs}$. on the cart is 0.146 inches. This is almost five times greater than with no weight on the cart. The ranges for all moves on a motor with the three different weights is the same as for $550 \mathrm{lbs}$. because the ranges coincide. However, for all other cases the ranges don't coincide and, therefore, the range for the three different weights is greater than the range for $550 \mathrm{lbs}$.

Since the range for $550 \mathrm{lbs}$. on the cart generally is greater than the range for no weight or $300 \mathrm{lbs}$. on the cart, and doesn't coincide with the other ranges, the range for all moves or short moves is better (about $1 / 2$ ) for the cart with no weight and 300 lbs. than for all three weights. For example, the range for moves from a short distance to the right to a position in the middle of a motor is 0.056 inches for all three weights, but improves to 0.026 inches (about $1 / 2$ ), if only no weight and $300 \mathrm{lbs}$. on the cart are considered. In the MPF no weight to $300 \mathrm{lbs}$. or less may be a sufficient range in weight. Handling greater than $300 \mathrm{lbs}$. (425 lbs. gross weight) in a glovebox would be extremely unusual. In the PIP only the trays and furnace bottom application required weights above this range.

For most cases the range for the tests with the cart centered on the gap between motors, is not as good as the same tests on the center of the motor. The one exception is all moves on a motor gap, but otherwise the ranges are about double the equivalent tests on the center of a motor.

Most of the tests were programmed in move commands. In move commands the maximum speed can be programmed, but accelerations and decelerations cannot. With the software provided by MagneMotion, changes in programmed maximum speed produced no perceivable change in actual maximum speed, even when extremely low maximum speeds were programmed. The maximum speed for all move commands was measured to be about $200 \mathrm{ft}$./minute.

With profile commands, the maximum speed, acceleration and deceleration can be programmed. This is traditional servo motion control. The maximum speed is actually controlled properly by profile commands. To determine if profile commands could improve repeatability over move commands, tests using profile commands were conducted. One test was run with $550 \mathrm{lbs}$. on the cart, stopping in the center of a motor with three different maximum speeds $(0.1 \mathrm{~m} / \mathrm{sec}, 0.5 \mathrm{~m} / \mathrm{sec}$ and $1.0 \mathrm{~m} / \mathrm{sec})$. The accelerations and decelerations for all three were numerically about half of the maximum speed. The results are shown in Attachment 7 . The ranges were not as good as the corresponding test using move commands as shown in Attachment 5. This is especially true if the fast from left or fast from right moves are compared, since the fast speed in a profile command $(1 \mathrm{~m} / \mathrm{sec})$ is equivalent to the actual speed (200 ft./min) with a move command. A second test was conducted using the moderate maximum speed, $0.5 \mathrm{~m} / \mathrm{sec}$ and three different decelerations $(-0.050$ 


\section{WSRC-TR-2002-00401}

$\mathrm{m} / \mathrm{sec}^{2},-0.200 \mathrm{~m} / \mathrm{sec}^{2}$, and $\left.-1.000 \mathrm{~m} / \mathrm{sec}^{2}\right)$. Again, the ranges were not as good as the corresponding test using move commands.

Some of the programs would stop during the first cycle or the first few cycles during the initial testing. In these cases, intermediate stop positions in the program (not the final stop position to determine repeatability) were changed until the program would run reliably. This changed the distance from which the cart would approach the final stop position. After the test was completed, it was determined that the program would stop because the cart was not positioned within the acceptable stop limit set in other software. The acceptable stop limit was increased and several programs that previously would not run continuously ran continuously.

\section{CONCLUSIONS}

Repeatability of the linear synchronous motor cart system was excellent. The tests determined that the repeatability for all moves for the cart system when stopping on the center of a motor with a range of gross weight from 125 to $675 \mathrm{lbs}$. was \pm 0.073 inches $( \pm 1.8 \mathrm{~mm})$. This is excellent repeatability for a cart carrying such a wide range of loads. This repeatability can be improved to \pm 0.028 inches $( \pm 0.7 \mathrm{~mm})$, if the load stops at a position completely on a motor unit and always approaches the point from a fixed distance from the same direction. If the gross weight only varies from $125 \mathrm{lbs}$. to $300 \mathrm{lbs}$., the repeatability on the motor can be further improved to \pm 0.013 inches $( \pm 0.3 \mathrm{~mm})$. This may be more indicative of the MPF weight range requirements.

Repeatability of the cart when stopping over a one inch gap between motors is about double that for similar situations when stopping over the center of a motor. However, the one inch gap is to allow for flanges between gloveboxes sections, air lock doors or fire doors. For the PIP, MPF and other glovebox facilities, it is unlikely that the cart would need to stop at all in these areas and it is extremely unlikely that the cart would need to stop accurately in these areas. In an actual application, the motors can be installed without gaps in a processing glovebox. Unfortunately, eliminating one or more gaps in the SRTC system to test repeatability with this configuration would require significant mechanical modification of the system and a substantial change in software by the vendor, MagneMotion. So repeatability at the joint between motors, with no significant gap was not tested. Theoretically, no gaps between motors should make the joint between motors insignificant, so repeatability should be similar to repeatability at the center of a motor.

The profile command did not produce as good a repeatability as the move command, even though the profile command allows the accelerations and decelerations to be changed.

The changes in the maximum velocity of the cart in move commands make no perceivable change in the actual maximum velocity of the cart. In fact the actual 
maximum velocity is about $200 \mathrm{feet} / \mathrm{sec}$ and is much faster than is probably desired in a glovebox system. The vendor software used for this test was the preliminary issue, since the QuickStick ${ }^{\mathrm{TM}}$ was a new product at the time of purchase. This software inadequacy needs to be corrected before it can be used in an actual glovebox system.

\section{SUMMARY}

The linear synchronous motor cart system has an advantage over conventional cart systems for a glovebox system because it has no moving parts other than the cart and wheels inside the glovebox. The repeatability tests documented in this report indicate that the linear synchronous motor cart system also has excellent repeatability. By always approaching a desired position from a short distance in one direction the repeatability for gross loads from $125 \mathrm{lbs}$. to $425 \mathrm{lbs}$. can be \pm 0.013 inches. The linear synchronous motor cart system should continue to be considered for use in the Modern Pit Facility. 
LSM repeatability test, no weight on cart, moves to center of motor

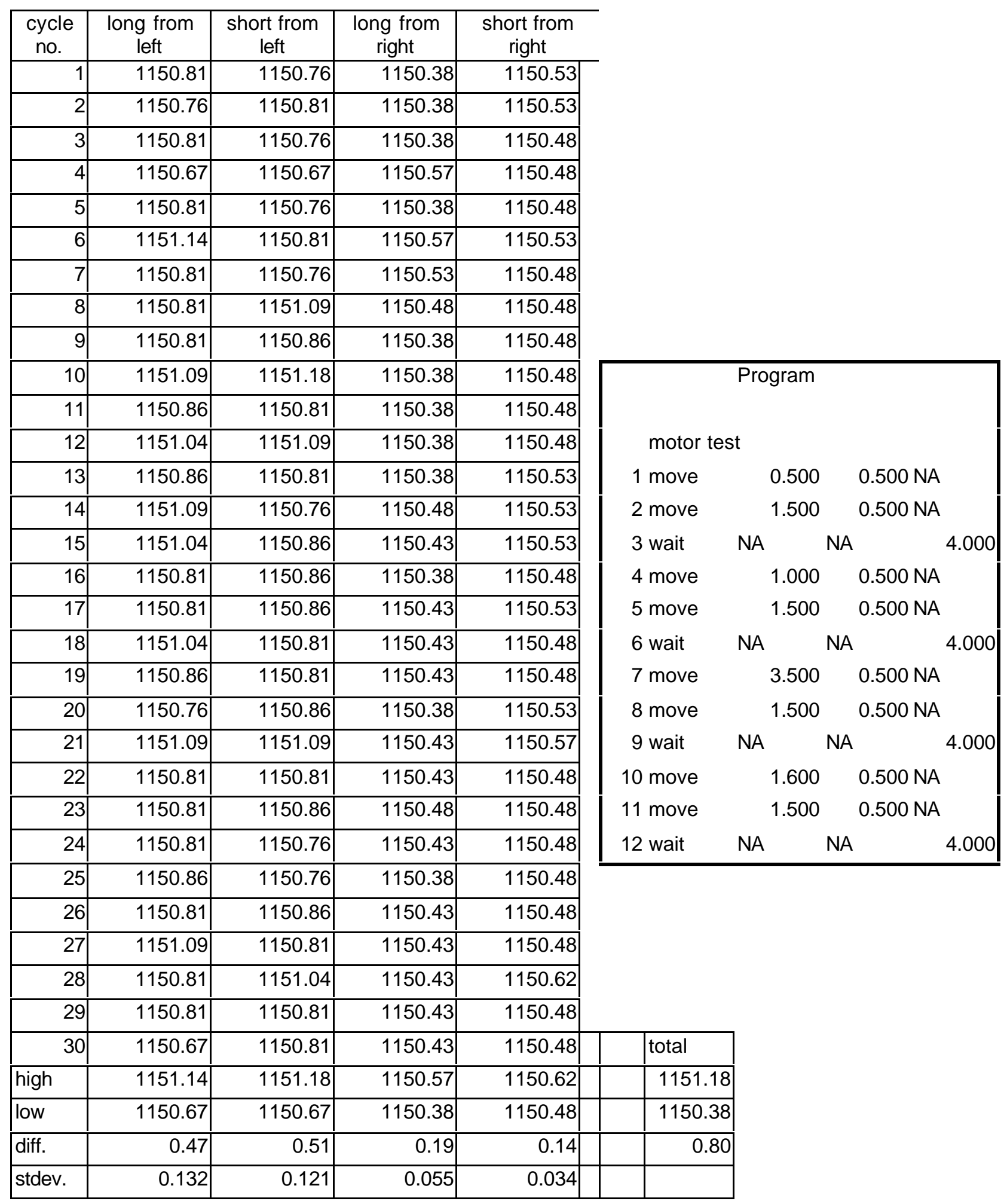


LSM repeatability test, no weight on cart, moves to gap between motors

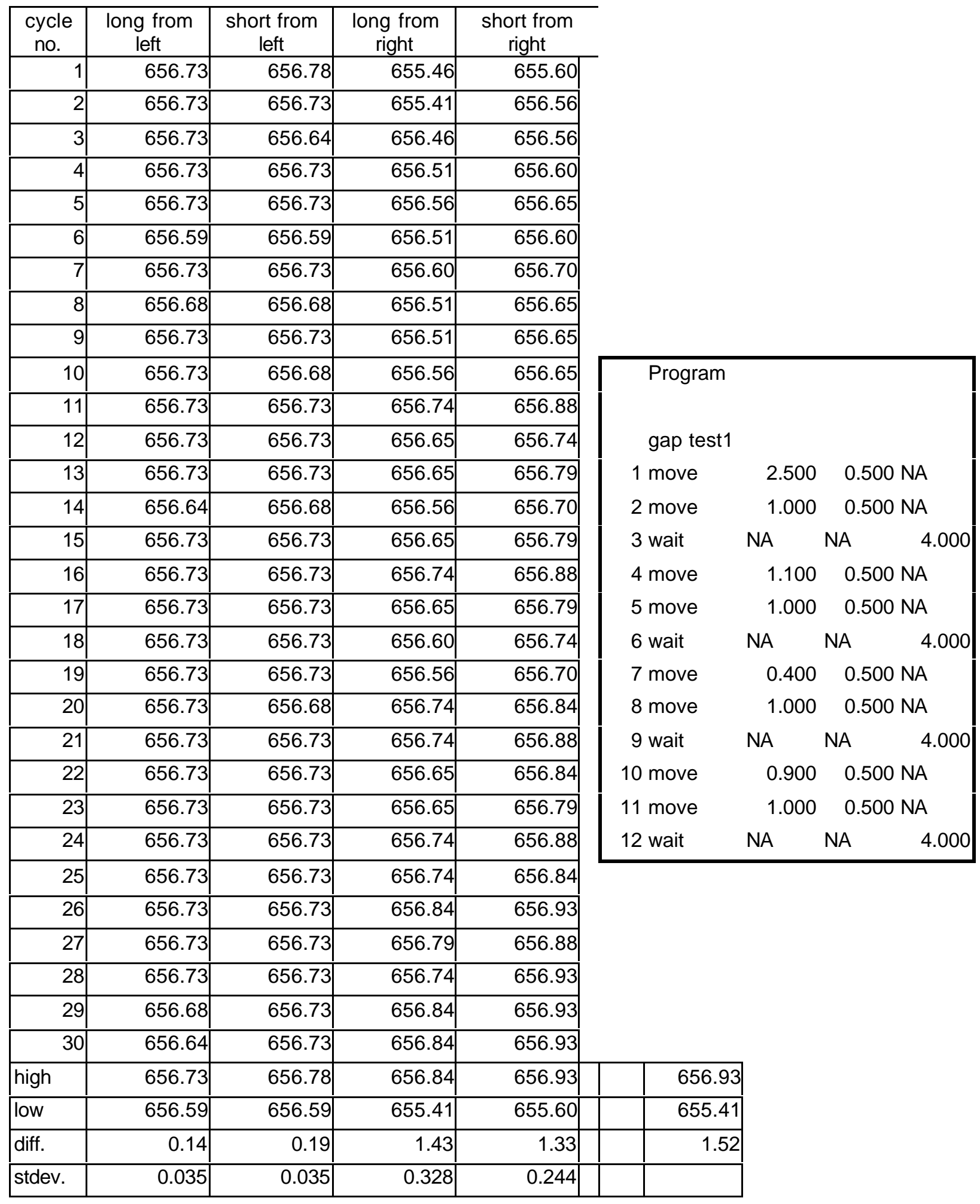


LSM repeatability test, 6 plates on cart ( 300 lbs.), moves to center of motor

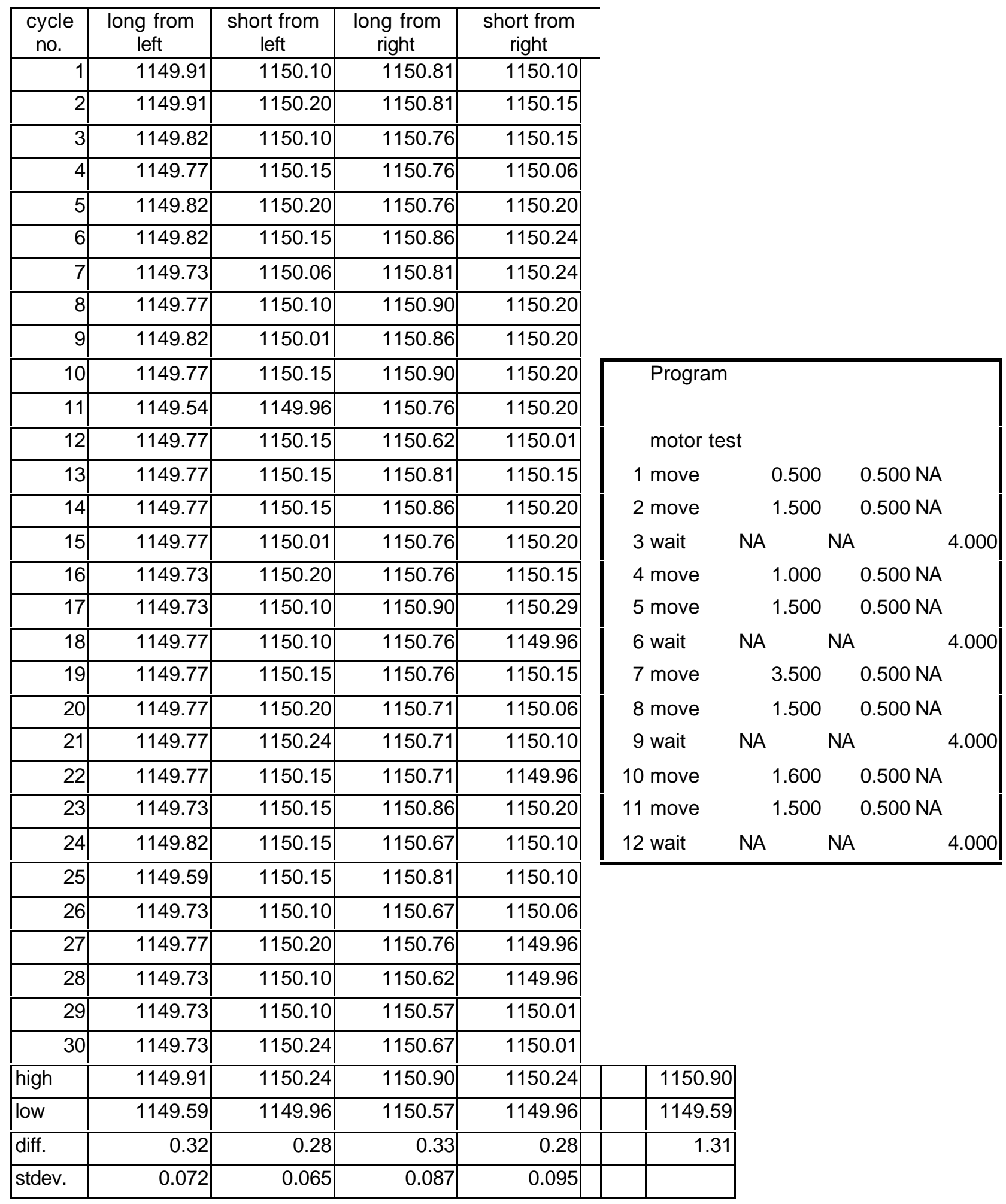


LSM repeatability test, 6 plants on cart ( 300 lbs.), moves to gap between motors

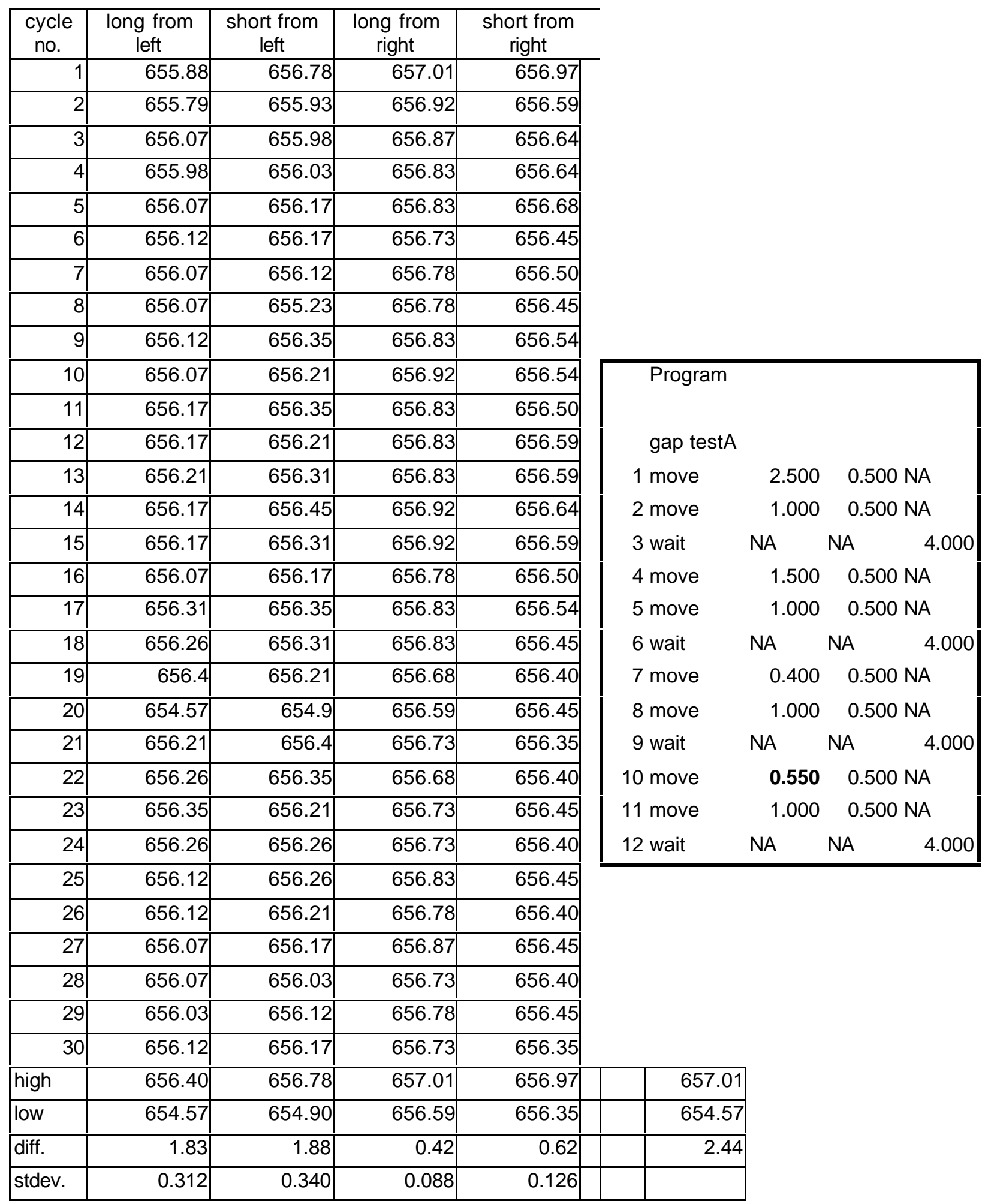


LSM repeatability test, 11 plates on cart ( $\sim 50 \mathrm{lbs}$.), moves to center of motor

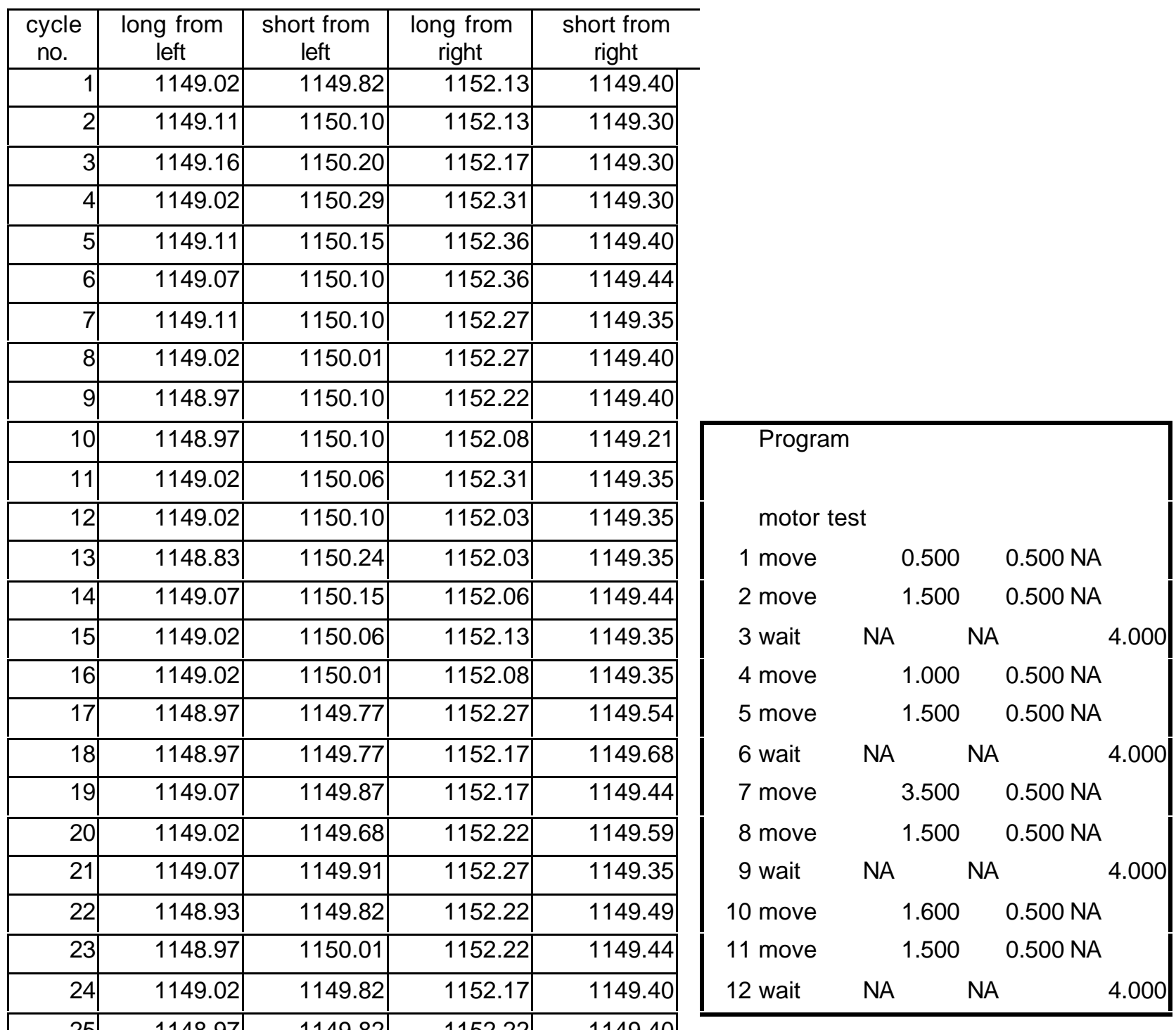

\begin{tabular}{|c|c|c|c|c|c|}
\hline 25 & 1148.97 & 1149.82 & 1152.22 & 1149.40 & \\
\hline 26 & 1149.07 & 1149.62 & 1152.36 & 1149.49 & \\
\hline 27 & 1149.02 & 1150.24 & 1152.22 & 1149.35 & \\
\hline 28 & 1148.97 & 1149.77 & 1152.22 & 1149.44 & \\
\hline 29 & 1148.74 & 1149.59 & 1152.36 & 1149.54 & \\
\hline 30 & 1148.83 & 1149.68 & 1152.45 & 1149.59 & total \\
\hline high & 1149.16 & 1150.29 & 1152.45 & 1149.68 & 1152.45 \\
\hline low & 1148.74 & 1149.59 & 1152.03 & 1149.21 & 1148.74 \\
\hline diff. & 0.42 & 0.70 & 0.42 & 0.47 & 3.71 \\
\hline stdev. & 0.088 & 0.199 & 0.107 & 0.101 & \\
\hline
\end{tabular}


LSM repeatability test, 11 plates on cart ( 550 lbs.), moves to gap between motors

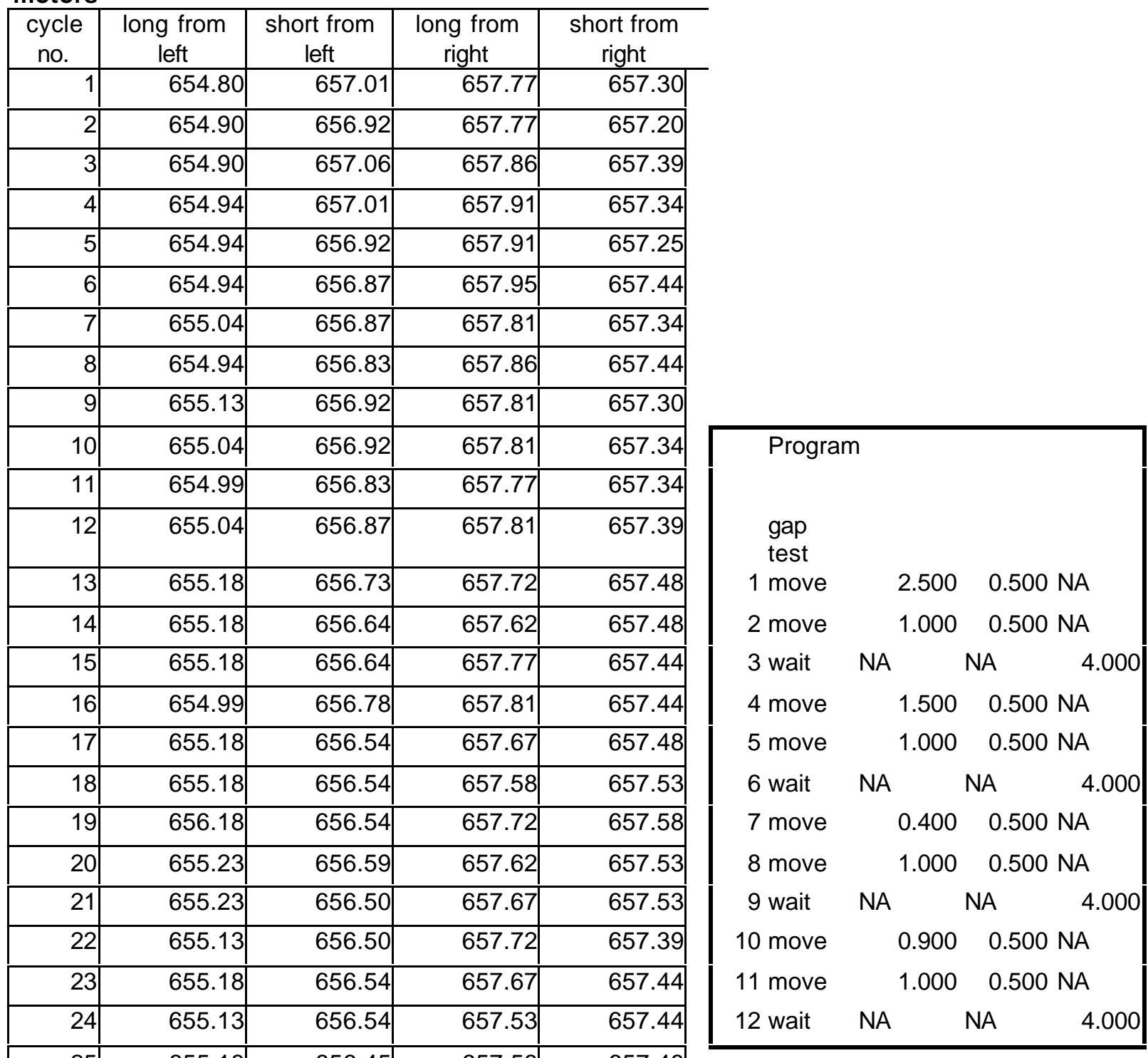

\begin{tabular}{|c|c|c|c|c|c|}
\hline 25 & 655.18 & 656.45 & 657.58 & 657.48 & \\
\hline 26 & 655.27 & 656.45 & 657.62 & 657.58 & \\
\hline 27 & 655.32 & \begin{tabular}{|c|}
656.50 \\
\end{tabular} & 657.62 & 657.62 & \\
\hline 28 & 655.23 & 656.50 & 657.62 & 657.58 & \\
\hline 29 & 655.32 & \begin{tabular}{|c|}
656.50 \\
\end{tabular} & 657.72 & 657.62 & \\
\hline 30 & 655.37 & 656.50 & 657.62 & 657.58 & total \\
\hline \begin{tabular}{|l|} 
high \\
\end{tabular} & 656.18 & \begin{tabular}{|c|}
657.06 \\
\end{tabular} & 657.91 & 657.62 & 657.91 \\
\hline low & 654.80 & 656.45 & 657.53 & 657.20 & 654.90 \\
\hline diff. & 1.38 & 0.61 & 0.38 & 0.42 & 3.01 \\
\hline stdev. & 0.243 & 0.200 & 0.111 & 0.110 & \\
\hline
\end{tabular}


LSM repeatability test, 11 plates on cart ( $550 \mathrm{lbs}$.), moves to center of motor

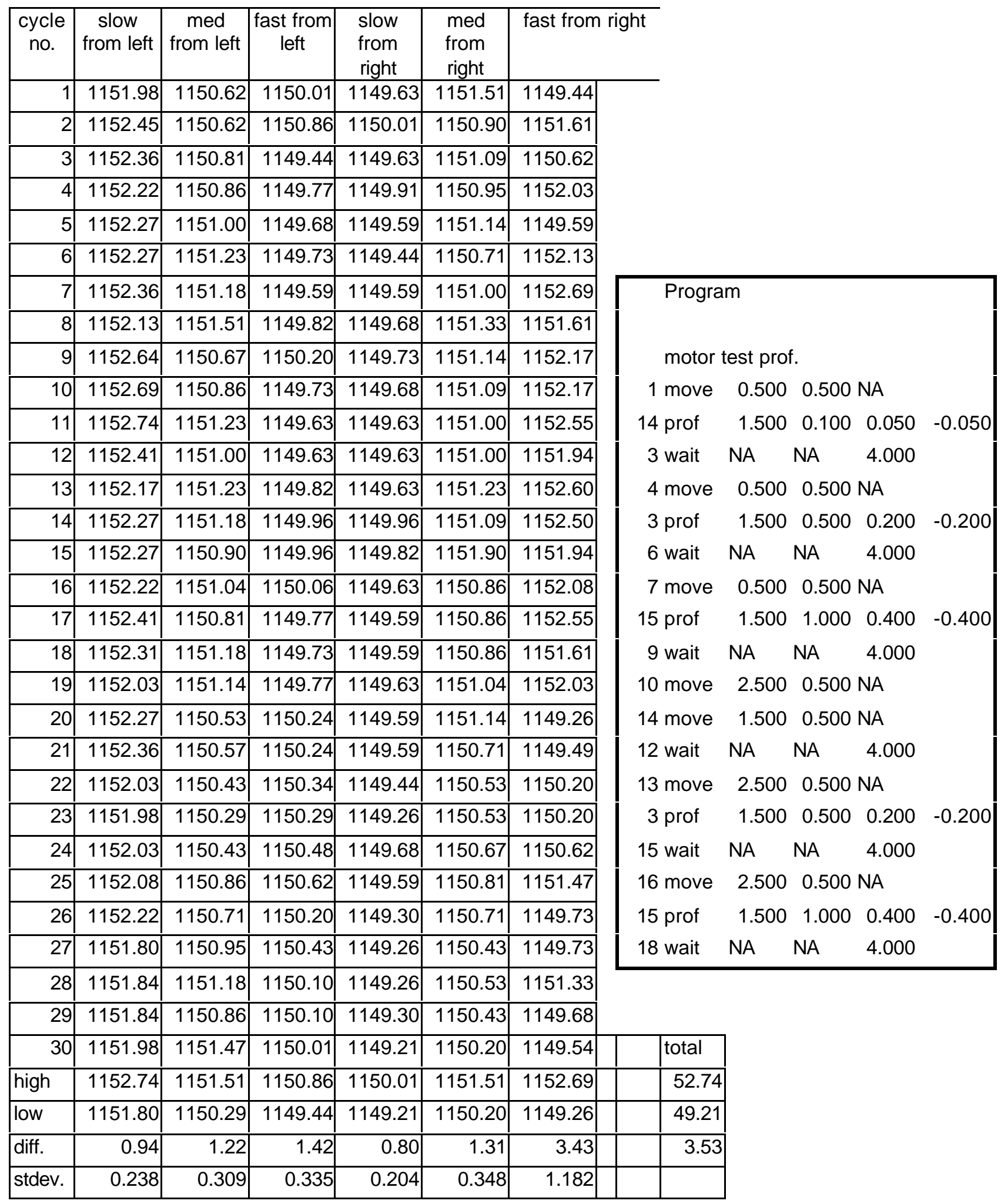


LSM repeatability test, 11 plates on cart ( $\sim 50 \mathrm{lbs}$.), moves to center of motor

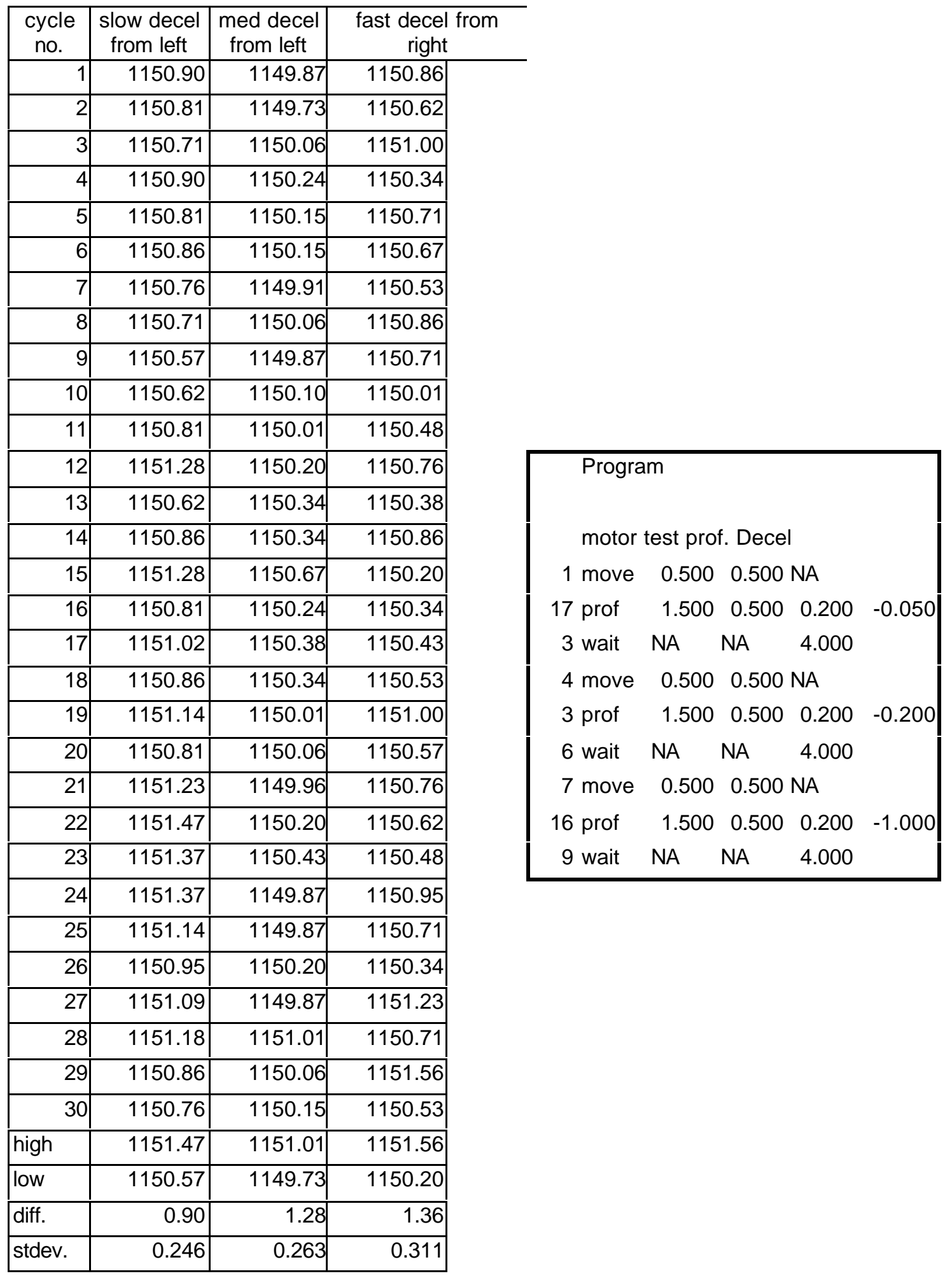

